\title{
Benefits and Consequences of Testosterone Replacement Therapy: A Review
}

Polackwich AS ${ }^{1}$, Tadros NN ${ }^{1}$, Ostrowski KA ${ }^{1}$, Hedges $\mathrm{JC}^{2}$

1. Urology Resident, 2. Assistant Professor, Department of Urology, Oregon Health \& Science University, Portland, OR, USA.

\begin{abstract}
Late onset hypogonadism (LOH) is an issue of increasing concern. Studies have shown the importance of testosterone in the maintenance of homeostasis, especially with respect to bone health, sexual function, diabetes, cardiovascular risk, mental health and cognition. Much of the dysfunction in hypogonadism can be reversed or improved with testosterone replacement therapy (TRT). Physicians worry about the possible consequences of TRT, especially regarding the prostate. By reviewing the literature, we have found there are significant benefits to TRT, and fears of adverse effects on the prostate are largely unfounded, though there is a great need for larger studies with longer periods of follow-up, especially to evaluate adverse events.
\end{abstract}

\section{Keywords}

Late onset hypogonadism ( $(\mathrm{OH})$, testosterone replacement, hormone replacement, testosterone, aging

Disclosure: The authors have no conflicts of interest to declare.

Received: 25 December 2012 Accepted: 21 January 2013 Citation: European Endocrinology, 2013;9(1):59-64 DOI:10.17925/EE.2013.09.01.59

Correspondence: A Scott Polackwich Jr., MD, Department of Urology, Oregon Health \& Science University, 3303 SW Bond Ave, CH10U, Portland, OR 97223, US.

E: polackwi@ohsu.edu

\section{Introduction}

In our increasingly aged population, late-onset hypogonadism (LOH) is an important public health issue with an incidence estimated at 12.3 cases per 1000 person years. ${ }^{1}$ There is an increased public knowledge of this condition and more patients are approaching their physicians about diagnosis and treatment.

Late-onset hypogonadism is an important clinical entity that should not be ignored by practitioners. It is associated with osteoporosis, ${ }^{2}$ frailty, ${ }_{1}{ }^{3}$ oss of libido and erectile dysfunction, ${ }^{4}$ depression, ${ }^{5}$ cognitive dysfunction, ${ }^{6}$ even cardiovascular disease ${ }^{7}$ and metabolic syndrome. ${ }^{8}$ Many patients and practitioners have lingering questions about the risks and benefits of this therapy as well as its use in certain populations, such as patients who have had prostate cancer or voiding dysfunction. While the use of testosterone in patients with a history of prostate cancer is currently contraindicated and considered off label use, many studies have started to evaluate it. Here we provide a review of testosterone replacement therapy (TRT); the benefits of this treatment and the risks it may pose.

\section{Testosterone and Erectile Dysfunction}

The incidence of erectile dysfunction (ED) is increasing ${ }^{9}$ along with the incidence of hypogonadism. ${ }^{10}$ Links between the two have been found on epidemiologic and basic science levels. After controlling for cofounders such as diabetes and vascular disease that typically occur in this population, the Massachusetts Male Aging Study found an increase in ED with decreasing testosterone among 625 patients, especially with luteinizing hormone (LH) levels $>8$ IU/I. ${ }^{11}$ Overall sexual dysfunction, especially ED has been associated with testosterone levels up to $8 \mathrm{nmol} / \mathrm{L}$ in a study of 2838 men. ${ }^{12}$ The effect of testosterone on ED is even more important in those with metabolic syndrome..$^{13}$

Endothelial dysfunction appears to be the main mechanism by which testosterone deficiency increases the incidence of ED. ${ }^{14}$ Studies in rats have shown decreased cavernosal tissue apoptosis in diabetic rats when treated with testosterone. ${ }^{15}$ similar effects are seen in humans and studies have found testosterone is important in tissue remodeling and maintenance of smooth muscle in erectile tissue. Lateonset hypogonadism alters this hormonal support and may increase progenitor cell differentiation into adipocytes. ${ }^{16}$ This translates into an increase in arterial stiffness and arteriogenic ED in patients with lateonset hypogonadism. 17,18

In addition to $\mathrm{LOH}$ being a risk factor for development of ED, multiple studies have found improvement in ED with TRT. Animal studies have found improvement in nitric oxide (NO) synthase and erections after TRT therapy. ${ }^{19}$ In human studies, improvement in IIEF scores can be seen after as little as 3-6 months of testosterone replacement therapy (TRT) alone. ${ }^{20,21}$ This improvement in erectile function, along with multiple other indices of sexual function (libido, ejaculatory function and bother), have been found to improve quickly with TRT, and continue to improve for 12 months in an evaluation of 849 patients in a large multicenter registry. ${ }^{4}$

One study that evaluated patients' response to TRT after maximal titration of phosphodiesterase type 5 inhibitors (PDE5I) found no additional improvement, though patients were not significantly hypogonadal, and these patients had good initial response to PDE5Is.22 In patients with $\mathrm{LOH}$ who have previously failed oral PDE5I therapy however, TRT has been found to improve responsiveness to PDE5Is. ${ }^{23}$ Penile doppler studies have shown this is likely by improvement of vasodilatory response to PDE5Is. ${ }^{24}$ This may save patients from being advanced to more invasive ED management such as intracavernosal injections and penile prosthesis placement. Evidence also suggests that early TRT may help in post prostatectomy ED ${ }^{25}$ (use in this population is currently contraindicated). With this evidence, patients with refractory ED should be evaluated for hypogonadism as evidence suggests there is a clinical benefit to concurrent treatment. 


\section{Effects on Metabolic Syndrome}

Hypogonadism, due to $\mathrm{LOH}$ or androgen depravation therapy, has been associated with an increase in adiposity, especially visceral fat, ${ }^{26}$ development and worsening of diabetes, ${ }^{27}$ and dyslipidemia. ${ }^{28}$ The connection between ED, diabetes and hypogonadism is so strong; some authors have suggested that presence of two should drive investigation for the presence of the third. ${ }^{29}$ Obesity itself can induce a secondary hypogonadism, feeding this cycle of worsening metabolic syndrome and continued hypogonadism. There is some evidence TRT may be able to interrupt this cycle. ${ }^{30,8}$

As these markers of metabolic syndrome are associated with hypogonadism, TRT has been found to improve these measures. ${ }^{31}$ In a randomized controlled trial (RCT) evaluating TRT and metabolic syndrome in 24 patients, TRT was found to improve fasting glucose, HgA1C, waist circumference and total cholesterol. ${ }^{32}$ A similar RCT of 38 patients also found decreases in subcutaneous fat mass with TRT ${ }^{33}$ Not all studies have shown this effect however, a RCT in 26 men found no difference in metabolic syndrome measures over a one year treatment period. ${ }^{34}$ While TRT is not a magic bullet against metabolic syndrome, it is clear that there is interplay between metabolic syndrome and hypogonadism in which TRT can likely play a positive role. ${ }^{35}$

\section{Cardiac Health}

Low testosterone has been associated with increased cardiovascular disease (CVD) and decrease in the surrogate markers for cardiovascular health. The Massachusetts Male Ageing Study (MMAS) evaluated 3518 men for over 17 years. Men with low total testosterone had a twofold risk for all-cause mortality and CVD death. ${ }^{7}$ A similar prospective populationbased study of 1954 men showed that low serum testosterone levels were independently associated with an increased risk of all-cause mortality and serum levels of testosterone were inversely related to CVD mortality. ${ }^{36}$ The Health in Men Study had similar findings; lower free testosterone and higher LH levels were associated with CVD mortality. ${ }^{37}$

Even in younger, middle-aged patients, higher testosterone is associated with favorable cardiovascular risk profile (lower levels of triglycerides, insulin, systolic blood pressure, and higher levels of HDL-cholesterol) in two large meta-analyses. ${ }^{38-40}$ The first by Araujo and colleagues felt that low endogenous testosterone was associated with increased risk of all cause and CVD mortality however there was significant differences in cohort selection and these may have played an effect on the results..$^{39}$ The other by Haring et al delineated the data to exclude comorbidities and showed a link between mortality risk and testosterone level even when strictly adjusting for comorbidities ${ }^{40}$

Testosterone replacement has shown possible benefits from a cardiac standpoint. A prospective study found an improvement in mortality independent of comorbidities in 587 patients with type 2 DM followed for $5.8 \mathrm{yrs}$. The mortality improved from $20 \%$ in the untreated group to $9.1 \%$ in the treated group. ${ }^{41}$ Similar results were also seen in a study from seattle with 1031 men with a decrease in mortality from $21 \%$ to $10 \%$ with treatment over the course of the study. ${ }^{42}$ While improvements in cardiac mortality have been seen in multiple population studies, the effect of testosterone in patients at high risk of cardiac death has yet to be studied in depth.

Not all studies have shown improvement though, an increase in cardiovascular events with TRT was found in a study by Basaria et al. while evaluating the effect of TRT in a frail population. The study was terminated early due increased cardiac events in the treatment arm. Some providers reference this study as a reason to avoid TRT. But, there were important differences in the patient populations that may account for this. The treatment group had statistically significant higher rates of hyperlipidemia, statin and antihypertensive use as well as trends towards greater preexisting cardiovascular disease, hypertension and hypertriglyceridemia. Due to these concerns, one should be wary about drawing widely applicable conclusions from this study. ${ }^{43}$

\section{Muscle Mass and Fragility}

Frailty and decreases in muscle strength worsen as men age, a process that is accelerated by changes in testosterone metabolism. An evaluation of 1445 men as part of the Framingham offspring Study found that free testosterone was positively associated with physical performance and decreased risk of developing limitation in mobility and further worsening of mobility over a 6.6 year period. ${ }^{3}$ These findings were seen again in a study of 1586 patients who had an average of 5.3 years follow up which found association of low free testosterone and frailty, this study also found a connection between this frailty and all-cause mortality. ${ }^{44}$

TRT has been shown to reverse this to some extent. Dose related increase in skeletal muscle mass and strength have been found in a study of 44 hypogonadal men treated with testosterone. ${ }^{45}$ This increase in muscle mass is also accompanied by increased lipid oxidation, improving overall lean body mass. ${ }^{46}$ An RCT of 274 hypogonadal frail men found not only increase in strength after six months of TRT, but also increase in quality of life as well. ${ }^{47}$

While some question the clinical relevance of these increases in strength, patients themselves find that these improvements are meaningful to them and their daily living, especially in patients with limited mobility. ${ }^{48}$ Frailty and loss of strength is an important clinical issue in the aging male, and studies have shown this process can be accelerated in hypogonadism and slowed with testosterne replacement therapy.

\section{Bone Health}

Along with muscle loss and frailty, there is a concern for falls and fractures in ageing populations. Multiple studies show that age related bone loss is associated with decreased serum levels of circulating sex hormones. ${ }^{49-51,2}$ The Osteoporotic Fractures in Men Study (MrOS) evaluated 1,469 men and showed older men with high SHBG and Iow bioavailable testosterone have a higher risk of fracture (HR 2.1). ${ }^{2}$ The Longitudinal Ageing Study Amsterdam (LASA) evaluated 623 men and 634 women aged 65-88 years and found that low levels of bioavailable estradiol and testosterone were found to be associated with high bone turnover, low BMD and higher risk of osteoporotic fractures in both men and women. ${ }^{52}$

TheeffectofTRTonbonemineral density(BMD) issomewhatcontroversial because two double blind, placebo-controlled studies with 237 and 39 patients found no changes in BMD with six months followup. ${ }^{53,54}$ Each of these studies evaluated men who had very minor hypogonadism, and treatment times were short. Even so, there was evidence of suppression of bone resorption. ${ }^{53}$ Longer studies have shown much better results regarding improvement in bone health. Three long term studies involving 99, 163 and 60 patients respectively found improvements in BMD at follow up ranging from 12-42 months. ${ }^{55-57}$ In the largest of these, Wang and colleagues found an increase in spine BMP by $3.8 \%$ at 30 months which was statistically 
Table 1: Testosterone Replacement Therapy After Prostate Cancer Treatment

\begin{tabular}{|c|c|c|c|c|c|c|c|}
\hline Author & Year & Patient Number & Treatment & F/U (months) & Pre-treatment TT & $\begin{array}{l}\text { Post-treatment } \\
\text { TT }\end{array}$ & Outcomes \\
\hline Agarwal et al. ${ }^{84}$ & 2005 & 10 & $\mathrm{RP}$ & 19 & 197 ng/dl & $591 \mathrm{ng} / \mathrm{ml}$ & No detectable PSA \\
\hline Kaufman et al. ${ }^{85}$ & 2004 & 7 & $\mathrm{RP}$ & * & $146 \mathrm{ng} / \mathrm{ml}$ & $438 \mathrm{ng} / \mathrm{ml}$ & No detectable PSA \\
\hline Khera et al. ${ }^{86}$ & 2009 & 57 & $\mathrm{RP}$ & 13 & $255 \mathrm{ng} / \mathrm{dl}$ & $459 \mathrm{ng} / \mathrm{dl}$ & No detectable PSA \\
\hline Morales et al. ${ }^{87}$ & 2009 & 5 & EBRT & 14.5 & $5.2 \mathrm{nmol} / \mathrm{L}$ & $17.6 \mathrm{nmol} / \mathrm{L}$ & $\begin{array}{l}\text { All PSA }<1.5 \text {, one } \\
\text { transitory increase }\end{array}$ \\
\hline Sarosody et al.$^{88}$ & 2007 & 31 & Brachytherapy & 36 & 188 ng/dl & $498 \mathrm{ng} / \mathrm{dl}$ & $\begin{array}{l}\text { All PSA }<1,74 \% \\
<0.1 . \text { one transient } \\
\text { increase }\end{array}$ \\
\hline Pastuszak et al. ${ }^{89}$ & 2012 & 13 & $\begin{array}{l}\text { EBRT/ Brachy- } \\
\text { therapy }\end{array}$ & 29.7 & $178 \mathrm{ng} / \mathrm{dl}$ & $368 \mathrm{ng} / \mathrm{dl}$ & $\begin{array}{l}\text { Mean PSA rose } \\
\text { from } 0.3 \text { to } 0.66 \text {, not } \\
\text { significant. }\end{array}$ \\
\hline
\end{tabular}

Overview of studies evaluating TRT in patients who have had previous treatment for prostate cancer. *length of follow up not reported for all patients. RP= radical prostatectomy. $E B R T=$ external beam radiation therapy. $T T=$ total testosterone.

higher than what was seen at six months. ${ }^{57}$ These studies underline the importance of testosterone's role in osteoporosis and continued therapy to reap the long term benefits of treatment.

\section{Testosterone Replacement and Depression}

The relationship between low levels of testosterone and depression is significant in older men; up to $40 \%$ of men with treatment-resistant depression suffer from low testosterone. ${ }^{5} \mathrm{~A}$ study of 3413 men from a general population found that men with testosterone deficiency had a higher symptom score, particularly regarding anxiety. ${ }^{58}$

Uncovering hypogonadism in the depressed patient is important because of its implications for treatment. Many studies have shown that testosterone replacement in hypogonadal men with depression improves their symptoms, including five randomised, placebo controlled, double-blinded studies. ${ }^{59-63}$ Patients in those studies showed a significant improvement in depressive symptoms (as measured by the Hamilton Rating Scale for Depression, HAM-D) with correction of the patient's hypogonadism.

Some excellent data also comes from the Testim Registry in the United States (TRIUS), a large, pharmaceutical sponsored multicenter, prospective, observational cohort registry, overall, $92.4 \%$ of the 762 men demonstrated some level of depressive symptoms, with $17.3 \%$ having moderately severe to severe symptoms. Testosterone levels and PHQ-9 (a validated self-report questionnaire) scores improved significantly by three months and at 12 months PHQ-9 scores showed a clinically meaningful mean improvement. Patients with moderately severe to severe symptoms decreased to $2.1 \%$ from $17.3 \% .{ }^{64}$ Other studies have shown testosterone works synergistically with other treatment modalities in treatment-resistant depression. ${ }^{59}$

\section{Testosterone Replacement and Cognition}

Sex hormones, including testosterone, play a protective role in cognition and brain function. Studies of elderly men have reported a positive association between free testosterone and a variety of cognitive tests that assess verbal, visual and working memory. Visuospatial function is positively associated with endogenous testosterone levels in at least three different studies using three different assessment scores. ${ }^{6,65,66}$
In one longitudinal cohort of 907 men followed for almost ten years, higher baseline FT were associated with better verbal and visual memory and processing speed. ${ }^{67}$

Several studies had shown declines due to androgen depravation therapy (ADT) in executive functions and visuospatial abilities; however, many of these have been inconsistent in their findings often suffering from low sample size and inadequate controls. ${ }^{68} \mathrm{~A}$ recent prospective Iongitudinal study with a relatively large population of nonmetastatic prostate cancer patients and controls evaluated ADT effects on cognition using 14 cognitive tests covering eight unique domains. By 12 months, ADT users had small but significantly lower scores in immediate span of attention, working memory and visuospatial function compared to controls. ${ }^{69}$

There are few studies examining the effect of TRT on cognition in patients with LOH. Two studies consisting of 207 and 44 patients followed for 6-12 months respectively and found no improvement in cognitive functions. ${ }^{70,71}$ In the paper by Kenny et al., there was some association between total testosterone at the end of the study and improvement in visual attention and task switching (Trailmaking B) suggesting there may be a slight beneficial effect of TRT. ${ }^{71}$ The interplay between hormones and cognition is likely complex and the benefits of TRT on cognition are not yet fully elucidated.

\section{Testosterone, PSA and Prostate Cancer}

The effect of testosterone on prostate cancer is perhaps the most feared potential consequence of TRT. Currently, a history of prostate cancer, or current prostate cancer, is a contraindication for TRT and the use of testosterone in these patients is considered 'off-label'. Since Huggins and Hodges' seminal work on the effect of castration on prostate cancer, physicians have been leery that exogenous testosterone could fuel prostate cancer development and growth. ${ }^{72}$ Further studies then demonstrated increase in prostate cancer growth and worsening of symptoms in patients taking testosterone. ${ }^{73}$ What many of these studies failed to differentiate was the difference between testosterone supplementation in those who were castrate and those who were hypogonadal. With a linear model of testosterone's effect on the prostate, there is little difference between the two, but with a saturation 
model, the difference between these two situations is very important. ${ }^{74}$ Morgentaler and colleagues suggested that prostate cancer cells, like typical prostate cells, reach a saturation point beyond which additional testosterone does not have added effect. ${ }^{75}$ In this way, testosterone metabolism within the prostate is not intuitive. Dihydrotestosterone (DHT) supplementation has been found in a RCT to not increase the intraprostatic concentrations of DHT even with significant increases in serum $\mathrm{DHT}^{76} \mathrm{~A}$ RCT of 44 patients comparing intraprostatic hormonal levels found no increase in T or DHT concentrations after six months of treatment despite appropriate serum increases in $\mathrm{T}^{.7}$

As a surrogate for prostatic response to exogenous testosterone, PSA has little response to TRT. A study of 187 patients over the age of 45 were followed for one year and found no significant change in PSA with TRT. ${ }^{78}$ Khera et al. found in a review of the Testim registry that PSA levels can rise with TRT, but only in patients who are severely hypogonadal defined as $T<250 \mathrm{ng} / \mathrm{dL}$, and these patients experienced only a modest rise in PSA of $0.32 . .^{79}$ In this same population, the authors found no difference in PSA in patients who started with a serum $\mathrm{T}$ of $250 \mathrm{ng} / \mathrm{dL} .80$

Currently, testosterone has not been found to increase in the incidence of prostate cancer development, in fact, prostate cancer incidence has been found to be higher in patients with lower serum testosterone. ${ }^{81}$ In patients on TRT a longitudinal study by Coward et al. evaluated PSA trends and prostate cancer development in 81 hypogonadal men who were followed for 36 months, and found minimal change in PSA and age appropriate incidence rates of prostate cancer. ${ }^{82} \mathrm{~A}$ large systemic review by Shabsigh et al evaluated 11 placebo controlled and 29 nonplacebo controlled randomized studies in patients with no history of prostate cancer; there was no relation to development of prostate cancer, Gleason grade or clinical stage. ${ }^{83}$ Even in patients with PIN on previous prostate biopsy, no significant increase in either PSA or incidence of prostate cancer is seen with TRT. ${ }^{84}$

TRT after treatment of prostate cancer is perhaps the most encountered question. In low risk prostate cancer without evidence of residual disease, many patients who previously received treatment for $\mathrm{LOH}$ are eager to restart medication. There is currently no evidence that TRT causes the proliferation of microscopic residual disease and increases recurrence rates. The previously mentioned systemic review by Shabsigh also examined four papers with patients who had prostate cancer, and found no increase in recurrence rates or disease progression. ${ }^{83}$ Surgical treatment of prostate cancer perhaps gives the best way to monitor for adverse outcomes with TRT as PSA can easily be followed as either detectable or not. Initial studies involving TRT after radical prostatectomy (RP) involved only 10 and 7 patients. ${ }^{85,86}$ One of the largest studies by Khera and colleagues followed 57 men for an average of 36 months after RP and 13 months after TRT initiation. ${ }^{87}$ None of these studies had any patients with detectable PSA or recurrence at last follow-up.

Evaluating TRT effect on prostate cancer after radiation treatment is not as easy as after surgery due to the complexities of following PSA after radiation. There are few studies examining this question. A case series of five patients who had a follow up of 14.6 months on TRT had only one episode of transient increase in PSA and all PSA values remained under $1.5 \mathrm{ng} / \mathrm{ml} .{ }^{88}$ Sarosody et al. followed 31 patients for a mean of five years on TRT who were 4.5 years after brachytherapy. There was no progression of disease, and all patients had PSA $<1$ and $74 \%$ were undetectable at last follow-up. ${ }^{89}$ Pastuszak et al. also found no increase in PSA in 13 patients previously treated with either brachytherapy or EBRT at 29.7 months of follow up. ${ }^{90}$ These studies suggest that once patients have concluded radiation therapy and concurrent androgen depravation therapy, they are likely to be eligible to receive TRT, though more studies are needed.

More recently, studies are under way evaluating TRT in patients with known prostate cancer who have not been treated with any curative therapy. Initial case studies tracked PSA in patients with low risk prostate cancer (localized Gleason $3+3$ ), and found no substantive change in PSA with two years of follow up. ${ }^{91}$ While these studies are only preliminary, they suggest that prostate cancer growth in the setting of TRT is not rapid or uncontrollable. TRT in this setting should only be considered with institutional approval in the setting of an approved study or protocol.

Current studies have shown that prostate cancer's response to TRT within the physiologic ranges of testosterone is limited. One must be careful though, as studies are plagued with low patient numbers and short follow-up. While certain follow up periods may be adequate for other cancers, longer follow up time is required for studies in prostate cancer. While rapid disease progression has not been seen, long term disease progression or development of prostate cancer has not been rigorously studied. Because of this, use of testosterone in patients with a history of prostate cancer is still contraindicated and its use in this population is considered 'off-label'. In an opinion paper by Kirby et al., it was estimated that a study to determine whether TRT increases prostate cancer risk would require 6000 patients to be treated with testosterone or placebo for six years. Thus, the most important point we can take away from these current studies is the need for national level studies. ${ }^{92,93}$

\section{Testosterone and Benign Prostatic Conditions}

While practitioners are most concerned about TRT and its effect on prostate cancer, some consider voiding dysfunction or BPH to be a contraindication to TRT. As previously discussed, intraprostatic testosterone does not increase with serum testosterone levels.77 Additionally, PSA has only been found to increase slightly in severely hypogonadal patients with TRT. ${ }^{79}$ The saturation model of testosterone and the prostate would suggest that benign growth of the prostate should not be adversely affected by TRT. ${ }^{94}$

In men not taking exogenous testosterone, higher serum testosterone levels have been found to be associated with lower incidence of development of lower urinary tract symptoms (LUTS) over 20 years of follow-up. ${ }^{95}$ TRT has not been shown to increase growth of the prostate, and in fact, in multiple studies it has been found to improve LUTS, especially after taking into account the effect of comorbidities. Initial case series found no relation between TRT and LUTS. ${ }^{96}$ Larger case series found improvements in LUTS, especially in voiding symptoms. ${ }^{97,98}$ Shigehara et al performed an RCT with 46 patients evaluating the effect of TRT on IPSS, uroflowmetry and PVR and found a significant decrease in IPSS. 99

Due to 5-alpha reductase inhibitors' (5ARI) mechanism of action, one might expect that TRT would interfere with $\mathrm{BPH}$ treatment, but recent studies have found TRT also does not interfere with the action of 5ARIS. Previously, in men not on TRT, serum testosterone has not been found to relate to the effectiveness of Dutasteride. ${ }^{100}$ More recently, prostatic volume still responds as expected with Dutasteride administration in an RCT of 53 men with BPH. ${ }^{101}$ 


\section{Summary}

An increasing body of literature is showing that testosterone plays an important role in homeostasis and maintenance of bodily functions as we age. $\mathrm{LOH}$ is a common consequence of aging and has been associated with the development and progression of multiple disorders. More importantly, studies find that much of this loss can be reversed with TRT. Concerns about impact on the prostate appear unfounded, especially in light of new paradigms about testosterone metabolism in the prostate, specifically, the saturation model of testosterone's effect on the prostate. While no recent study has found an association between TRT and prostate cancer incidence, recurrence, or progression, these studies have relatively low patient numbers and short follow-up for prostate cancer studies. Thus, TRT is still contraindicated in this population. What are needed now are large RCTs to definitively answer these questions for patients and providers. ${ }^{102}$
Araujo AB, O'Donnell AB, Brambilla DJ, Simpson WB, et al., Prevalence and Incidence of Androgen Deficiency in MiddlePrevalence and Incidence of Androgen Deficiency in MiddleAged and Older Men: Estimates from the Massachusetts
Male Aging Study, I Clin Endocrinol Metabol, 2004;89:5920-6. Cawthon PM. Ensrud KE, Laughlin GA, Cauley JA, Dam T, fractures in men (MrOS) study, J Clin Endocrinol Metabol fractures in men (MrOS)
2009 Oct; $94(10): 3806-15$

3. Krasnoff JB, Basaria S, Pencina MJ, et al., Free Testosterone Levels Are Associated with Mobility Limitation and Physical Performance in Community-Dwelling Men: The Framingham Offspring Study, J Clin Endocrinol Metab, June 2010;95(6):2790-9

4. Khera M, Bhattacharya RK, Blick G, et al., Improved Sexual Function with Testosterone Replacement Therapy in Hypogonadal Men: Real-World Data from the Testim Registry in the United States (TRiUS), I Sex Med, 2011 Nov;8(11):3204-13, Yesavage JA, Davidson J, Widrow L, Berger PA, Plasma Testosterone Levels, Depression, Sexuality and Age, Biol Psychiatry, 1985;20:199-228

Christiansen K, Knussmann R, Sex Hormones and cognitive Functioning in Men, Neuropsychobiology, 1987;18(1):27-36 Stellato RK, Feldman HA, Hamdy O, et al., Testosterone, Sex Hormone-Binding Globulin, and the Development of Type 2 Diabetes in Middle-Aged Men: Prospective Results From the Massachusetts Male Aging Study, Diabet Care, 2000;23:490-4 Saad F, Gooren $\amalg$, The Role of Testosterone in the Etiology and Treatment of Obesity, the Metabolic Syndrome, and Diabetes Mellitus Type 2, J Obes, 2011;(2011). Article ID: 471584 Erectile Dysfunction in Men 40 to 69 Years Old: Longitudinal Erectile Dysfunction in Men 40 to 69 Years Old: Longitudina
Results from the Massachusetts Male Aging Study, J Urol, Results from the

10. Feldman HA, Longcope C, Derby CA, et al., Age Trends in the Level of Serum Testosterone and Other Hormones in MiddleAged Men: Longitudinal Results from the Massachusetts Male Aging Study, J Clin Endocrinol Metab, 2002;87:589.

11. Kupelian V, Shabsigh R, Travison TG, et al., Is There a Relationship Between Sex Hormones and Erectile Dysfunction? Results from the Massachusetts Male Aging Study, J Urol, 2006 Dec;176(6 Pt 1):2584-8.

12. O'Connor DB, Lee DM, Corona $\mathrm{G}$, et al. The Relationships Between Sex Hormones and Sexual Function in MiddleAged and Older European Men, $J$ Clin Endocrinol Metab, October 2011, 96(10):E1577-E1587.

13. Yeh $\mathrm{HC}$, Wang $\mathrm{CJ}$, Lee YC, et al., Association Among Metabolic Syndrome, Testosterone Level and Severity of Erectile Dysfunction, Kaohsiung J Med Sci, 2008 May;24(5):240-7.

14. Aversa A, Bruzziches R, Francomano D, et al., Endothelial Dysfunction and Erectile Dysfunction in the Aging Man, International Journal of Urology, 2010;17:38-47.

15. Mostafa T, Rashed LA and Kotb K, Testosterone and Chronic Sildenafil/Tadalafil Anti-Apoptotic role in Aged Diabetic Rats, International Journal of Impotence Research Diabetic Rats, Inter $2010 ; 22: 255-61$.

16. Traish AM, Kim N., Weapons of Penile Smooth Muscle Destruction: Androgen Deficiency Promotes Accumulation of Adipocytes in the Corpus Cavernosum, Aging Male, 2005 Sep-Dec;8(3-4):141-6.

17. Corona G, Mannucci E, Lotti F, et al., Pulse pressure, an Index of Arterial Stiffness, is Associated with Androgen Deficiency and Impaired Penile Blood Flow in Men with ED, J Sex Med, 2009 Jan;6(1):285-93.

18. Aversa A, Isidori AM, De Martino MU, et al., Androgens and Penile Erection: Evidence For a Direct Relationship Between Free Testosterone and Cavernous Vasodilation in Men with Erectile Dysfunction, Clinical Endocrinology, 2000;53:517-522.

19. Baba K, M. Yajima M, Carrier S, et al., Delayed Testosterone Replacement Restores Nitric Oxide Synthase-Containing Nerve Fibres and the Erectile Response in Rat Penis, BJU International, 2000:85:953-8.

20. Chiang HS, Cho SL, Lin YC, Hwang TI. Testosterone Gel Monotherapy Improves Sexual Function of Hypogonadal Men Mainly Through Restoring Erection: Evaluation by IIEF Score, J Urology. 2009 Apr;73(4):762-6.

21. Corona G, Petrone L, Fisher AD, et al., Six-month administration of $1 \%$ testosterone gel is able to restore erectile function in hypogonadal patients with erectile dysfunction function in hypogonadal patients with erect

22. Spitzer M, Basaria S, Travison TG, Davda MN, Effect of TesSpitzer M, Basaria S, Travison TG, Davda MN, Effect of Tes-
tosterone Replacement on Response to Sildenafil Citrate in tosterone Replacement on Response to Sildenafil Citrate in
Men With Erectile Dysfunction: A Parallel, Randomized Trial, Men With Erectile Dysfunction: A Parallel, Ran

23. Garcia JA, Sanchez PE, Fraile C, Escovar P, Testosterone undecanoate improves erectile dysfunction in hypogonadal men with the metabolic syndrome refractory to treatment men with the metabolic syndrome refractory to treatment
with phosphodiesterase type 5 inhibitors alone, Andrologia, with phosphodiesterase

24. Aversa A, Isidori AM, Spera G, Lenzi A, Fabbri A, Androgens improve cavernous vasodilation and response to sildenafil improve cavernous vasodilation and response to sildenatil
in patients with erectile dysfunction, Clinical Endocrinology, in patients with

25. Khera $\mathrm{M}$, Androgens and erectile function: a case for early androgen use in postprostatectomy hypogonadal men, J Sex Med, 2009 Mar;6 Suppl 3:234-8.

26. Katznelson L, Rosenthal DI, Rosol MS, et al., Using quantitative $C T$ to assess adipose distribution in adult men with acquired hypogonadism, AJR Am J Roentgenol, 1998 Feb;170(2):423-7.

27. Yeap BB, Chubb SA, Hyde Z, et al., Lower serum testosterone is independently associated with insulin resistance in non-diabetic older men: the Health In Men Study, Eur J Endocrinol. 2009 Oct;161(4):591-8

28. Garcia-Cruz E, Piqueras M, Huguet J, et al. Hypertension, dyslipidemia and overweight are related to lower testosterone levels in a cohort of men undergoing prostate biopsy, Int I Impot Res, 2012 May-Jun;24(3):110-3.

29. Tamler R, Deveney T, Hypogonadism, erectile dysfunction, and type 2 diabetes mellitus: what the clinician needs to know, Postgrad Med, 2010 Nov;122(6):165-75

30. Aftab SS, Kumar S, Barber T, The Role of Obesity and Type 2 Diabetes Mellitus in the development of Male Obesityassociated Secondary Hypogonadism, Clin Endocrinol (Oxf), 2012 Nov 3 (epub).

31. Lapauw $B$, Ouwens $M$, Hart LM, et al. Sex steroids affect triglyceride handling, glucose-dependent insulinotropic triglyceride handing, glucose-dependent insulinotropic clinical trial in healthy young men, Diabetes Care, 2010 Clinical trial in heal
Aug:33(8): $1831-3$.

32. Kapoor D, Goodwin E, Channer KS, Jones TH, Testosterone replacement therapy improves insulin resistance, glycaemic control, visceral adiposity and hypercholesterolaemia in hypogonadal men with type 2 diabetes, Eur J Endocrinol, June 1, 2006;154:899-906

33. Frederiksen L, Højlund K, Hougaard DM, et al., Testosterone therapy decreases subcutaneous fat and adiponectin in aging men, Eur J Endocrinol, 2012 Mar;166(3):469-76.

34. Agledahl I, Hansen JB, Svartberg J, Impact of testosteron treatment on postprandial triglyceride metabolism in elderly men with subnormal testosterone levels, Scand Clin Lab Invest, 2008;68(7):641-8.

35. McGill JJ, Shoskes DA, Sabanegh ES, Androgen deficiency in older men: Indications, advantages, and pitfalls of testosterone replacement therapy, Cleve Clin I Med, 2012 Nov;79(11):797-806.

36. Volzke HR, Steveling A, Krebs A, et al., Low serum testosterone levels are associated with increased risk of mortality in a population-based cohort of men aged 20-79, European Heart Journal, 2010 Jun; 31(12):1494-501.

Hyde Z, Norman PE, Flicker L, et al., Low free testosterone predicts mortality from cardiovascular disease but not other causes: the Health in Men Study, Journal of Clinical Endocrinology \& Metabolism, 2012 Jan; 97(1):179-89.

38. Firtser S. Juonala M, Magnussen CG, et al., Relation of total and free testosterone and sex hormone-binding globulin with cardiovascular risk factors in men aged 24-45 years, The Cardiovascular Risk in Young Finns Study, Atherosclerosis, 2012 May;222(1):257-62.

39. Araujo AB, Dixon JM, Suarez EA, et al., Clinical review: Endogenous testosterone and mortality in men: a systematic review and meta-analysis, Journal of Clinical Endocrinology \& Metabolism. 96(10):3007-19, 2011 Oct.

40. Haring R, Volzke H, Steveling A et al. Low serum testosterone levels are associated with increased risk of mortality in a population-based cohort of men aged 20-79, Eur Heart J, 2010;31:1494-501

41. Hackett $\mathrm{G}$, Testosterone and the heart, The international Journal of clinical practice, July 2012;66,7,648-55.

42. Shores MM, Smith NL, Forsberg CW, et al., Testosterone treatment and mortality in men with low testosterone, J Clin Endocrinol Metab, 2012 Jun;97(6)2050-8.

43. Basaria S, Coviello AD, Travison TG, Storer TW, Adverse events associated with testosterone administration, N Engl J Med, $2010 \mathrm{Jul}$ 8;363(2):109-22.

44. Hyde Z, Flicker L, Almeida OP, et al., Low Free Testosterone Predicts Frailty in Older Men: The Health in Men Study, $\mathrm{J}$ Clin Endocrinol Metab, 95:3165-72, 2010.

45. Storer TW, Woodhouse L, Magliano L, et al., Changes in Muscle Mass, Muscle Strength, and Power but Not Physical Muscle Mass, Muscle Strength, and Power but Not Physica
Function Are Related to Testosterone Dose in Healthy Older Men, I Am Geriatr Soc, 2008 Nov;56(11):1991-9.
46. Frederiksen L, Højlund K, Hougaard DM, et al., Testosterone therapy increased muscle mass and lipid oxidation in aging men, Age, 2012 Feb:34(1):145-56

47. Srinivas-Shankar U Roberts SA et al. Effects of testosterone on muscle strength, physical function, body composition, and quality of life in intermediate-frail and frail elderly men: a randomized, double-blind, placebo-controlled study, J Clin Endocrinol Metab, 2010 Feb;95(2):639-50.

48. Travison TG, Basaria S, Storer TW, et al., Clinical meaningfulness of the changes in muscle performance and physical function associated with testosterone administration in older men with mobility limitation, J Gerontol A Biol SCI Med Sci, 2011 Oct; 66(10):1090-9.

49. Risto O, Hammar E, Hammar K, et al., Elderly men with a history of distal radius fracture have significantly lower calcaneal bone density and free androgen index than agematched controls, Aging Male, 2012 Mar;15(1):59-62.

50. Szulc P, Hawa G, Boutroy $S$, et al., Cortical bone status is associated with serum osteoprotegerin concentration in men: the STRAMBO study, Journal of Clinical Endocrinology \& Metabolism, $2011 \mathrm{Jul} ; 96(7): 2216-26$

51. Rariy CM, Ratcliffe SJ, Weinstein R, et al., Higher serum free testosterone concentration in older women is associated with greater bone mineral density, lean body mass, and total fat mass: the cardiovascular health study, Journal of

52. Kuchuk NO, van Schoor NM, Pluijm SM, et al., The association of sex hormone levels with quantitative ultrasound, tion of sex hormone levels with quantitative ultrasound fractures in older men and women, Clinical Endocrinology, 2007 Aug; 67(2):295-303

53. Merza Z, Blumsohn A, Mah PM, et al., Double-blind placebo-controlled study of testosterone patch therapy on bone turnover in men with borderline hypogonadism, International Journal of Andrology, 2006 Jun;29(3):381-91,

54. Emmelot-Vonk MH, Verhaar HJ, Nakhai Pour HR, et al., van der Schouw YT. Effect of testosterone supplementation on functional mobility, cognition, and other parameters in older men: a randomized controlled trial, JAMA, 2008 Jan;299(1):39-52

55. Kenny AM, Kleppinger A, Annis K, et al., Effects of transdemal testosterone on bone and muscle in older men with low bioavailable testosterone levels, low bone mass, and physical frailty, Journal of the American Geriatrics Society, 2010 Jun; $58(6): 1134-43$

56. Aversa A, Bruzziches R, Francomano D, et al., Migliaccio S. Effects of long-acting testosterone undecanoate on bone mineral density in middle-aged men with late-onset hypogonadism and metabolic syndrome: results from a 36 months controlled study, Aging Male, 2012 Jun;15(2):96-102.

57. Wang $\mathrm{C}$, Cunningham $\mathrm{G}$, Dobs $\mathrm{A}$, et al., Long-term testosterone gel (AndroGel) treatment maintains beneficial effects on sexual function and mood, lean and fat mass, and bone mineral density in hypogonadal men, Journal of Clinical Endocrinology \& Metabolism, 89(5):2085-98,

5. Clinical Endocrinology \& Metabolism, 89(5):2085-98, levels and psychological health status in men from a general population: the Tromsø study, Aging Male, 2004 May 14(1):37-41.

59. Pope HG Jr, Cohane GH, Kanayama G, et al., Testosterone gel supplementation for men with refractory depression: A randomized, placebo-controlled trial, Am J Psychiatry, 2003;160:105-11

60. Rabkin JG,Wagner GJ, Rabkin R, A double-blind, placebocontrolled trial of testosterone therapy for HIV-positive men with hypogonadal symptoms, Arch Gen Psychiatry, 2000;57:141-7.

61. Shores MM, Matsumoto AM, Sadak TI, et al., Testosterone replacement decreases depressive symptoms in older hypogonadal men with subsyndromal depression. Presentation at the American Association of Geriatric Psychiatry New Orleans, LA, March 4, 2007

62. Rabkin JG,Wagner GJ, MCElhiney MC, et al., Testosterone versus fluoxetine for depression and fatigue in HIV/ AIDS: A placebo-controlled trial, J Clin Psychopharmacol, 2004;24:379-85.

63. Seidman SN, Miyazaki M, Roose SP, Intramuscular testosterone supplementation to selective serotonin reuptake inhibitor in treatment-resistant depressed men: Randomized placebo-controlled clinical trial, I Clin Psychopharmacol, 2005;25:584-8.

64. Khera M, Bhattacharya RK, Blick $G$. et al., The effect of testosterone supplementation on depression symptoms in hypogonadal men from the Testim Registry in the US (TRiUS). Aging Male, 2012 Mar:15(1):14-21.

65. Driscoll I, Hamilton DA, Yeo RA, et al. Virtual navigation in 
humans: the impact of age, sex, and hormones on place learning, Horm Behav, 2005:47(3):326-35.

66. Thilers PP, Macdonald SW, Herlitz A, The association between endogenous free testosterone and cognitive performance: a population-based study in 35 to 90 year-old men and women, Psychoneuroendocrinology, 2006:31(5):565-76.

67 Moffat $\mathrm{SD}$, Zonderman $\mathrm{AB}$, Metter $\mathrm{E}$, et al , Longitudinal assessment of serum free testosterone concentration predicts memory performance and cognitive status in elderly men $J$ Clin Endo dictab, 2002:87(11):5001-7.

68. Tadros NN, Garzotto M, Androgen deprivation therapy for prostate cancer: not so simple, Asian I Androl, for prostate cancer. not
2011 Mar:13(2):187-8

69. Alibhai SM, Breunis $\mathrm{H}$, Timilshina $\mathrm{N}$, et al., Impact of androgen-deprivation therapy on cognitive function in men with nonmetastatic prostate cancer, I Clin Oncol, 2010;28:5030-7

70. Emmelot-Vonk MH, Verhaar HJ, Nakhai Pour HR, et al. Effect of testosterone supplementation on functional mobility, cognition, and other parameters in older men: a randomized controlled trial, JAMA, 2008 Jan 2;299(1):39-52.

71. Kenny AM, Bellantonio S, Gruman CA, et al., Effects of transdermal testosterone on cognitive function and health perception in older men with low bioavailable testosterone levels, J Gerontol A Biol Sci Med Sci, 2002 May:57(5):M321-5

72. Huggins $\mathrm{C}$, Hodges $\mathrm{CV}$, Studies on prostatic cancer, I: the effect of castration, of estrogen and of androgen injection on serum phosphatases in metastatic carcinoma of the prostate, Cancer Res, 1941:1.293-297.

73. Fowler JE, Whitmore WF, The response of metastatic adenocarcinoma of the prostate to exogenous testosterone, J Urol, 1981:126:372-5.

74. Morgentaler A, Testosterone and Prostate Cancer: An Historical Perspective on a Modern Myth, European Urology, torical Perspective on

75. Morgentaler A, Traish AM, Shifting the paradigm of testosterone and prostate cancer, the saturation model and the limits of androgen-dependent growth, Eur Urol, 2009;55:310-320.

76. Page ST, Lin DW, Mostaghel EA, et al., Dihydrotestosterone Administration Does Not Increase Intraprostatic Androgen Concentrations or Alter Prostate Androgen Action in Healthy Men: A Randomized-Controlled Trial, J Clin Endocrinol Metab, February 2011;96(2):430-

77. Marks LS, Mazer NA, Mostaghel E, et al., Effect of testoster- one replacement therapy on prostate tissue in men with late-onset hypogonadism: a randomized controlled trial, JAMA, 2006 Nov 15;296(19):2351-61.

78. El-Sakka Al, Hassoba HM, Elbakry AM, Hassan HA, Prostatic specific antigen in patients with hypogonadism: effect of testosterone replacement, J Sex Med, 2005 Mar;2(2):235-40.

79. Khera M, Miner M, Bhattacharya R, et al., PSA levels significantly rise after 3 months of testosterone replacement therapy in severely hypogonadal men in the Testim registry therapy in severely hypogonadal men in the Testim resing
in the US (TRIUS) cohort, J Urol, 2010;183(Suppl):e533.

80. Khera M, Bhattacharya RK, Blick G, et al. Changes in prostate specific antigen in hypogonadal men after 12 months of testosterone replacement therapy: support for the prostate saturation theory, J Urol, 2011;186(3):1005-11.

81. Morgentaler A, Rhoden EL, Prevalence of Prostate Cance Among Hypogonadal Men With Prostate-Specific Antige Levels of $4 \mathrm{ng} / \mathrm{ml}$ or Less, J Urology, 2006;68:1263-7.

82. Coward RM, Simhan J, Carson CC, Prostate-specific antigen changes and prostate cancer in hypogonadal men treated with testosterone replacement therapy, BJU International 2008;103:1179-83

83. Shabsigh R, Crawford ED, Nehra A, Slawin KM, Testosterone therapy in hypogonadal men and potential prostate cancer risk: a systematic review, Int J Impot Res, 2009;21:9-23.

84. Rhoden EL, Morgentaler A, Testosterone Replacement Therapy in Hypogonadal Men at High Risk for Prostate Cancer: Results of 1 Year of Treatment in Men with Prostatic Intraepithelial Neoplasia, J Urology, 2003;170:2348-51.

85. Agarwal PK, Oefelein MG. Testosterone Replacement Therapy after Primary Treatment for Prostate Cancer J Urology, Feb 2005;173:533-6.

86. Kaufman JM, Graydon RJ, Androgen Replacement after Curative Radical Prostatectomy for Prostate Cancer in Hyporonal Men, J Urology Sept 2004:172:920-2.

87. Khera M, Grober ED, Najari B, et al. Testosterone replacement therapy following radical prostatectomy, I Sex Med, ment therapy following

88. Morales M, Black AM, Emerson LE, Testosterone adminisMorales M, Black AM, Emerson LE, Testosterone administration to men with testosterone deficiency syndrome after external beam radiotherapy for localized prostate cancer: preliminary observations, BJU international, 2008;103:62-4. Sarosdy MF, Testosterone Replacement for Hypogonadis After Treatment of Early Prostate Cancer With Brachytherapy, Cancer, February 1 2007:109(3):536-41.

90. Pastuszak AW, Pearlman AM, Godoy G, et al., Testosterone replacement therapy in the setting of prostate cancer treated with radiation, International Journal of Impotence
Research, [epub. 13 September 2012]

91. Morgentaler A Two years of testosterone therapy associated with decline in prostate-specific antigen in a man with untreated prostate cancer, I Sex Med, 2009 Feb; 6(2):574-7.

92. Morales A, Effect of testosterone administration to men with prostate cancer is unpredictable: a word of caution and suggestions for a registry. BJU International, 2011;107:1369-73.

93. Kirby R, Gould D, Testosterone Replacement Therapy in Hypogonadal men and Prostate Cancer Risk, BJU International, 2005;96:471-6.

94. Polackwich AS, Ostrowski KA, Hedges JC, Testosterone Replacement Therapy and Prostate Health, Curr Urol Rep 2012:13:441-6.

95. Trifiro MD, Parsons JK, Palazzi-Churas K, et al., Serum sex hormones and the 20-year risk of lower urinary trac symptoms in community-dwelling older men, BJU Int, 2010;105(11):1554-9.

96. Takao T, Tsujimura A, Nakayama J, et al., Lower Urinary Tract Symptoms After Hormone Replacement Therapy in Japanese Patients with Late-onset Hypogonadism: A Preliminary Report, Int J Urol, 2009;16:212-4.

97. Haider H, Gooren $\mathrm{L}$, Padungtod P, Saad F, Concurrent improvement of the metabolic syndrome and lower urinary tract symptoms upon normalisation of plasma testosterone levels in hypogonadal elderly men, Andrologia, 2009;41(1):7-13.

98. Amano T, Imao T, Takemae $\mathrm{K}$, et al., Testosterone Replacement Therapy by Testosterone Ointment Relieves Lower Urinary Tract Symptoms in Late Onset Hypogonadism Patients, Aging Male, 2010;13(4):242-6.

99. Shigehara $\mathrm{K}$, Sugimoto $\mathrm{K}$, Konaka $\mathrm{H}$, et al., Androgen Replacement Therapy Contributes to Improving Lower Urinary Tract Symptoms in Patients with Hypogonadism and Benign Prostate Hypertrophy: a randomized controlled study, Aging Male, 2011;14(1):53-8.

100. Marberger M, Roehrborn CG, Marks LS, et al. Relationship among Serum Testosterone, Sexual Function, and the Response to Treatment in Men Receiving Dutasteride for Benign Prostatic Hyperplasia, J Clin Endocrinol Metab, 2006;91(4):1323-8

101. Page ST, Hirano L, Gilchriest J, et al., Dutasteride Reduces Prostate Size and Prostate Specific Antigen in Older Hypogonadal Men With Benign Prostatic Hyperplasia Undergoing Testosterone Replacement Therapy, J Urol,

102. Bremner WJ, Testosterone Deficiency and Replacement in Older Men, N Engl J Med, 2010;363:189-91. 